\title{
Giant granulomatous lesions of the femoral head and neck in rheumatoid arthritis
}

\author{
C. L. COLTON AND A. J. DARBY \\ London
}

Local areas of subarticular bone erosion occurring in rheumatoid arthritis are a typical manifestation of the disease (Cruickshank, Macleod, and Shearer, 1954; Steven 1949).

Occasionally they may be large enough to produce mechanical weakness, although the majority of spontaneous fractures in rheumatoid arthritis occur through uneroded areas of bone (Badley and Ansell, 1960). Such large osteolytic lesions may present diagnostic difficulties. This work presents two cases of rheumatoid arthritis where giant erosions of the femoral neck occurred, resulting in pathological fracture.

\section{Case reports}

\section{CASE 1}

A 66-year-old male was referred for orthopaedic opinion with a 33 year history of rheumatoid arthritis, the problem at the time of referral being fixed flexion of the knee preventing walking.

When seen he was taking Indomethacin $25 \mathrm{mg}$. three times a day and was not, nor had ever been, on corticosteroid therapy.

\section{Examination}

There was a $35^{\circ}$ flexion deformity of both knees with flexion to $120^{\circ}$ on the right and to $100^{\circ}$ on the left. He had severe rheumatoid involvement of elbows, wrists, and digital joints in both upper limbs.

Both hips had an almost full range of painless movement and the movements of feet and ankles were only slightly limited.

The erythrocyte sedimentation rate was $45 \mathrm{~mm} . / 1 \mathrm{st} \mathrm{hr}$ (Westergren) and the latex-fixation test was positive at a dilution of $1: 160$.

$X$-ray films of the hips at this time revealed wellcircumscribed, osteolytic lesions in the femoral head and neck on both sides (Fig. 1).

\section{Fracture}

He was therefore placed on the waiting list to be admitted for investigation and further assessment, but 8 days later, whilst walking downstairs at home, he felt sudden pain in the left hip and heard a loud crack. He was admitted to hospital the same day when he had the clinical features of a fracture of the left upper femur. $X$-ray films revealed that a displaced fracture had occurred through the osteolytic lesion in the left femoral neck (Fig. 2, opposite).

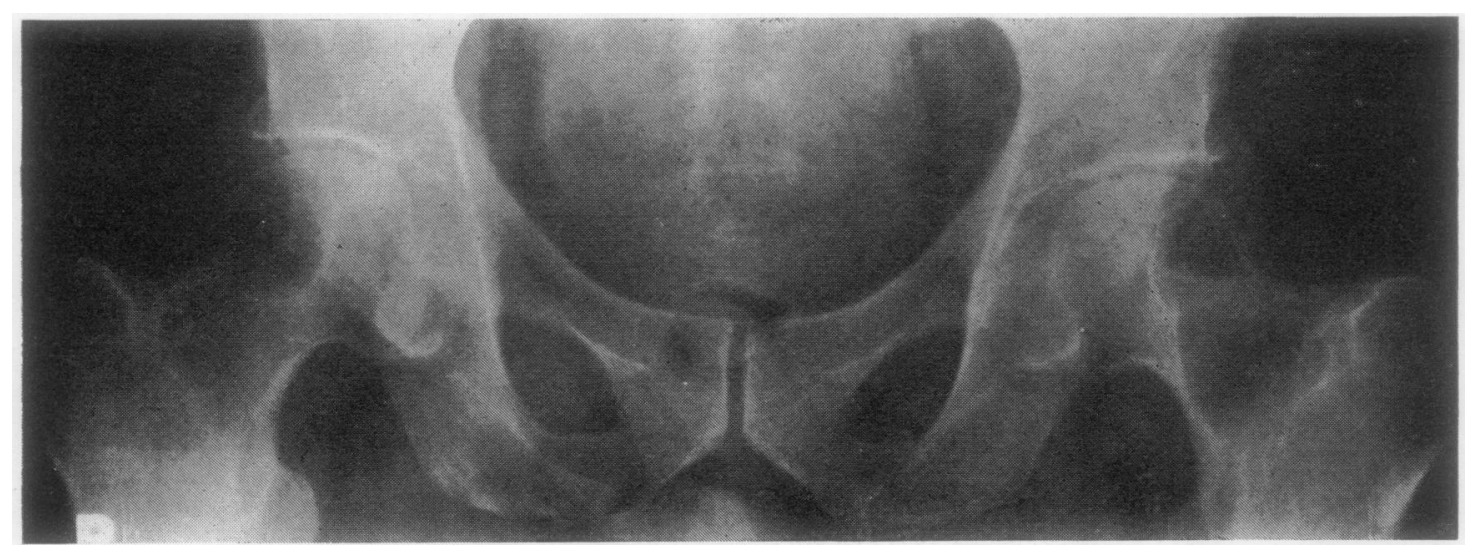

FIG. 1 Case 1. Radiograph of hips, showing well-circumscribed osteolytic lesions in head and neck of both femora. 


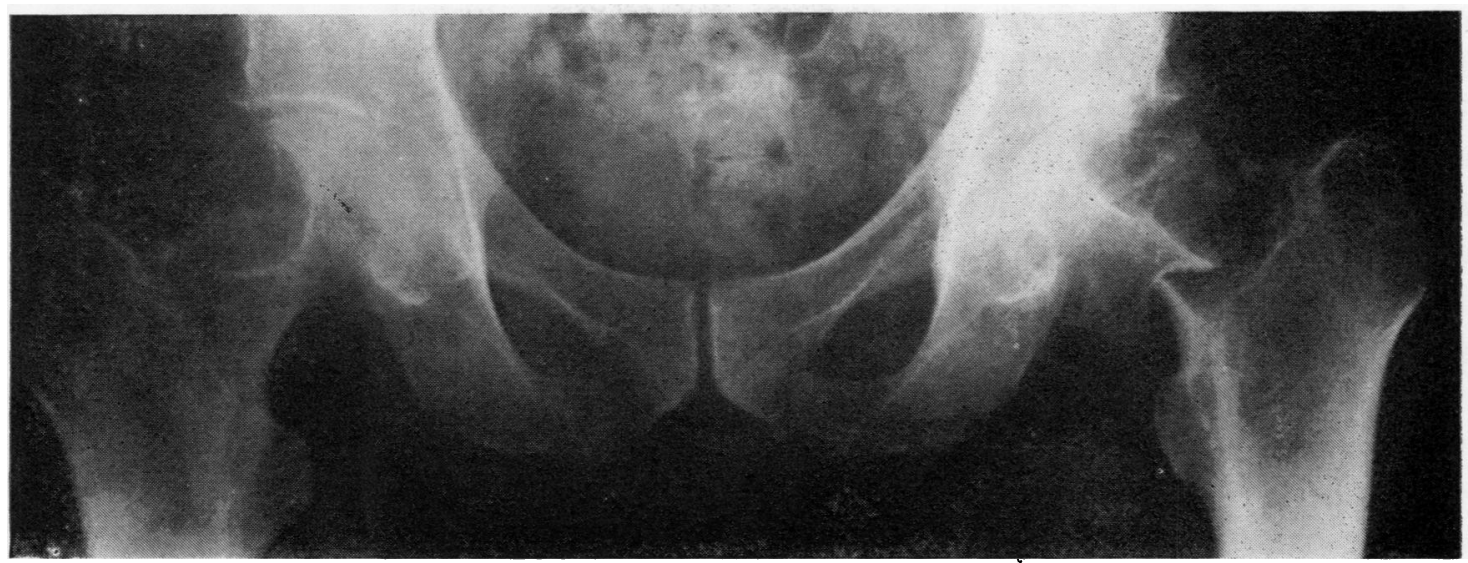

FIG. 2 Case 1. Later radiograph, showing a fracture through left femoral neck at site of osteolytic lesion.

\section{Treatment}

This was treated by excision of the left femoral head and neck and replacement with an Austin Moore prosthesis. At the time of operation the osteolytic lesion was found to be a smooth-walled, bony cavity lined by a thick membrane which was torn at the fracture site and filled with blood clot.

\section{Result}

Post-operatively he made uneventful progress and 3 months later he had a full range of left hip movement with no pain. He has subsequently undergone further surgery on his knees.

PATHOLOGY

The cancellous bone of the femoral neck was almost totally destroyed by an osteolytic lesion, $2 \cdot 5 \mathrm{~cm}$. diameter. The contents of the lesion consisted of soft brown tissue. A similar contiguous lesion, 1.5

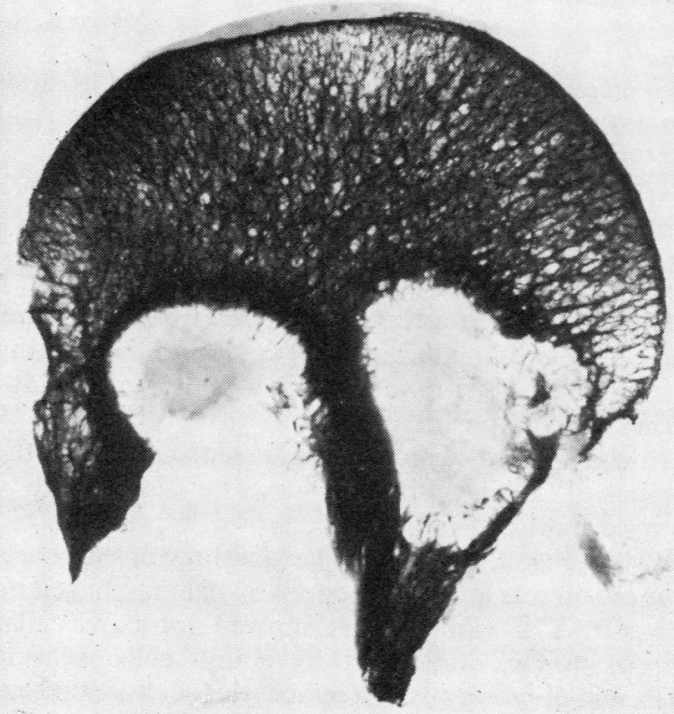

FIG. 3 Case 1. Radiograph of slice from femoral head and neck, showing osteolytic areas with sclerotic margins. $\mathrm{cm}$. diameter, was present in the head of the femur, and another, separate focus, $2 \mathrm{~cm}$. diameter, which had destroyed the femoral neck cortex at the articular margin (Fig. 3). The articular cartilage around the fovea was replaced by dark tissue and there were numerous small erosions around the articular margin (Fig. 4).

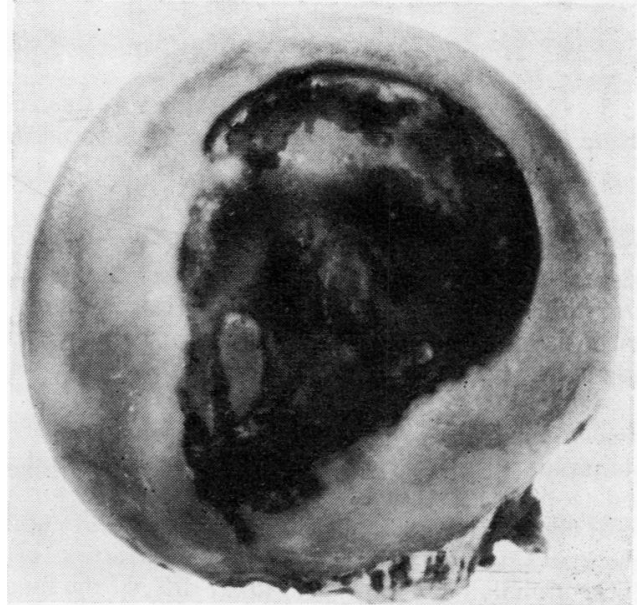

FIG. 4 Case 1. Photograph of articular surface of femoral head, showing replacement of articular cartilage around the fovea by haemorrhagic soft tissue

Histological sections of the articular surface were typical of rheumatoid arthritis. There was replacement of cartilage in the perifoveal region by vascular fibrous tissue, containing scattered foci of round cells, and occasional polymorphs. This tissue lay over bone in most places, but also covered cartilage peripherally. The osteolytic lesions consisted of densely collagenous fibrous tissue surrounded by sclerotic bone. In some places the fibrous tissue was separated from bone by a zone of fatty marrow. A sparse round cell infiltration was present (Fig. 5, overleaf). 


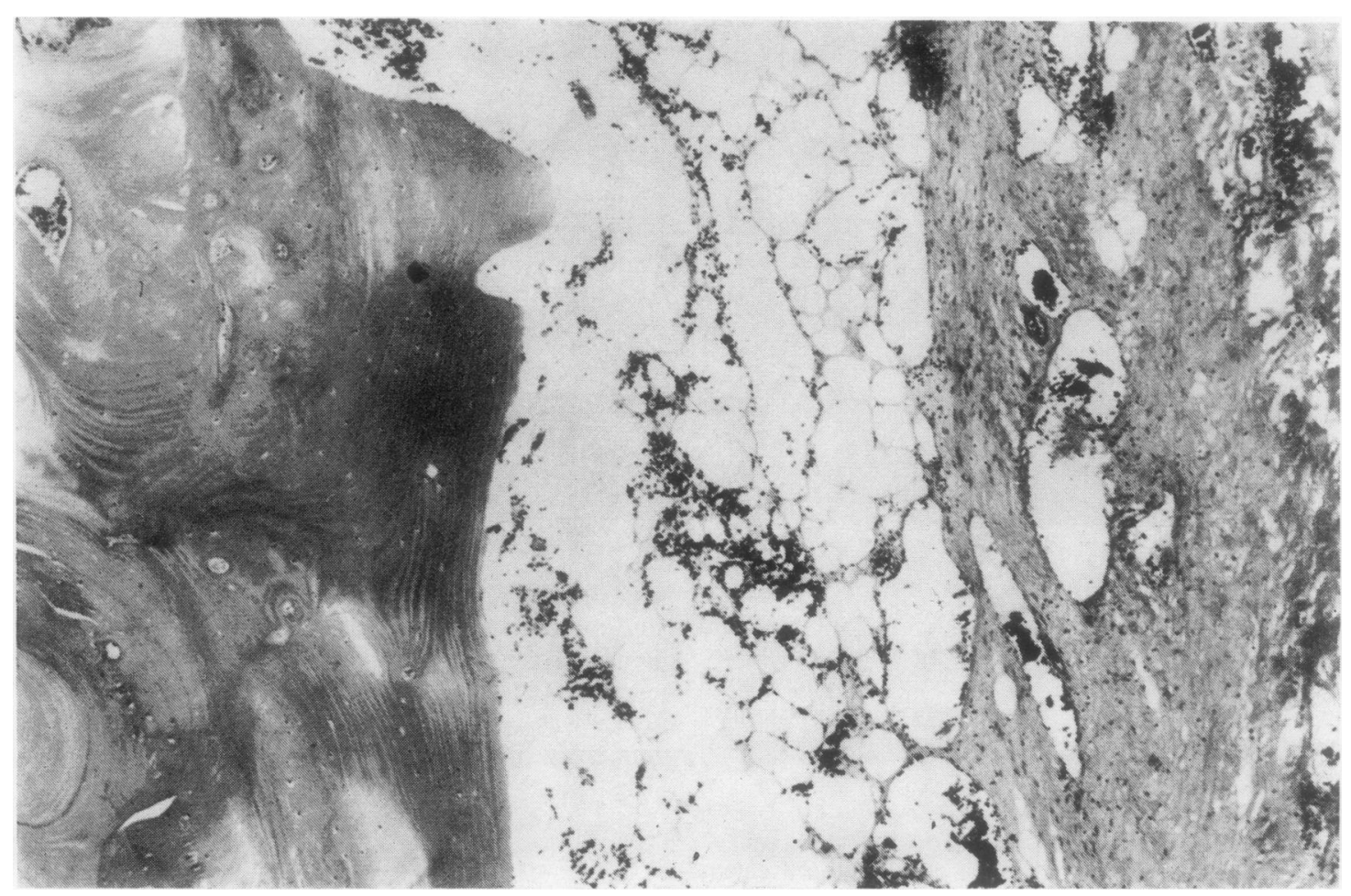

FIG. 5 Case 1. Photomicrograph of margin of osteolytic lesion. Dense fibrous tissue on the right is separated from sclerotic bone on the left, by a zone of fatty marrow. Haematoxylin and eosin. $\times 60$.

\section{CASE 2}

A 63-year-old male with a 6-year history of sero-positive rheumatoid arthritis, was admitted to hospital, having fallen 9 days previously when a chair on which he was sitting collapsed.

\section{Examination}

He complained of severe pain in the right hip and was found to have a fracture of the right upper femur. His general condition was good. He had rheumatoid changes in the knees, wrists, and hands, with subluxation of the metacarpophalangeal joints and ulnar drift of the fingers. On admission to hospital the erythrocyte sedimentation rate was $59 \mathrm{~mm}$./1st $\mathrm{hr}$ (Westergren), haemoglobin 11.8 $\mathrm{gm} . / 100 \mathrm{ml}$., with normal white cell and differential counts. The latex-fixation test was positive.

Radiology of the right hip revealed a large osteolytic lesion in the femoral head and neck and a fracture through this site. These appearances were thought to be highly suggestive of a metastatic deposit. (Fig. 6, opposite).

A radiograph taken 20 months previously (which was not available on admission) showed a small osteolytic lesion at the articular margin in the superior part of the femoral neck (Fig. 7, overleaf).

\section{Treatment}

The following day, the head and neck of the right femur were excised and a Thompson femoral head prosthesis was inserted, using Simplex acrylic cement.
The subsequent course was interrupted on the fourth post-operative day by a posterior dislocation of the prosthesis which was reduced with ease under general anaesthesia.

\section{Result}

The present clinical position is that 6 months after operation the patient had painless flexion of the right hip to $10^{\circ}$ above the right angle with no deformity.

This patient has never received steroid therapy.

\section{PATHOLOGY}

The femoral head showed replacement of the articular cartilage around the fovea by dark tissue, and a large bilocular osteolytic lesion containing soft haemorrhagic tissue occupied almost the width of the femoral neck.

Microscopical sections showed replacement of the perifoveal cartilage by fibrovascular tissue with a heavy round cell infiltration, typical of rheumatoid arthritis (Fig. 8, overleaf). The histology of the osteolytic lesion was largely obscured by haemorrhage and necrosis. The viable areas showed loose, vascular fibrous tissue, infiltrated by round cells, plasma cells, and polymorphs. Lymphocytic foci were present in the adjacent marrow. It appeared more cellular and less fibrous than in Case 1 and sclerosis of the 


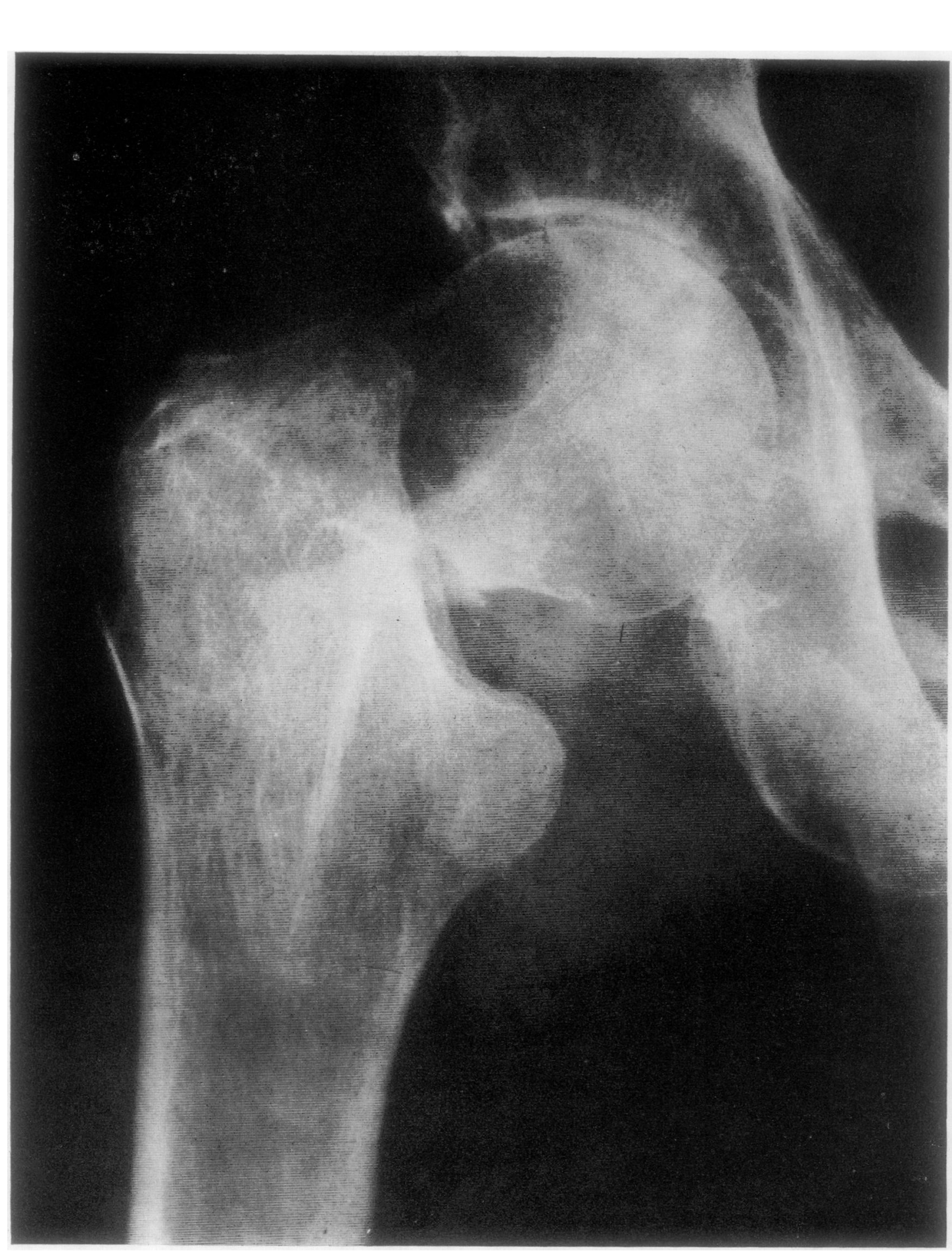

$\stackrel{10}{0}$

กิ

\%

ก

오

웅

市

항

$\overrightarrow{0}$

FIG. 6 Case 2. Radiograph of right hip, showing a similar osteolytic lesion in femoral neck with a pathological fracture. 


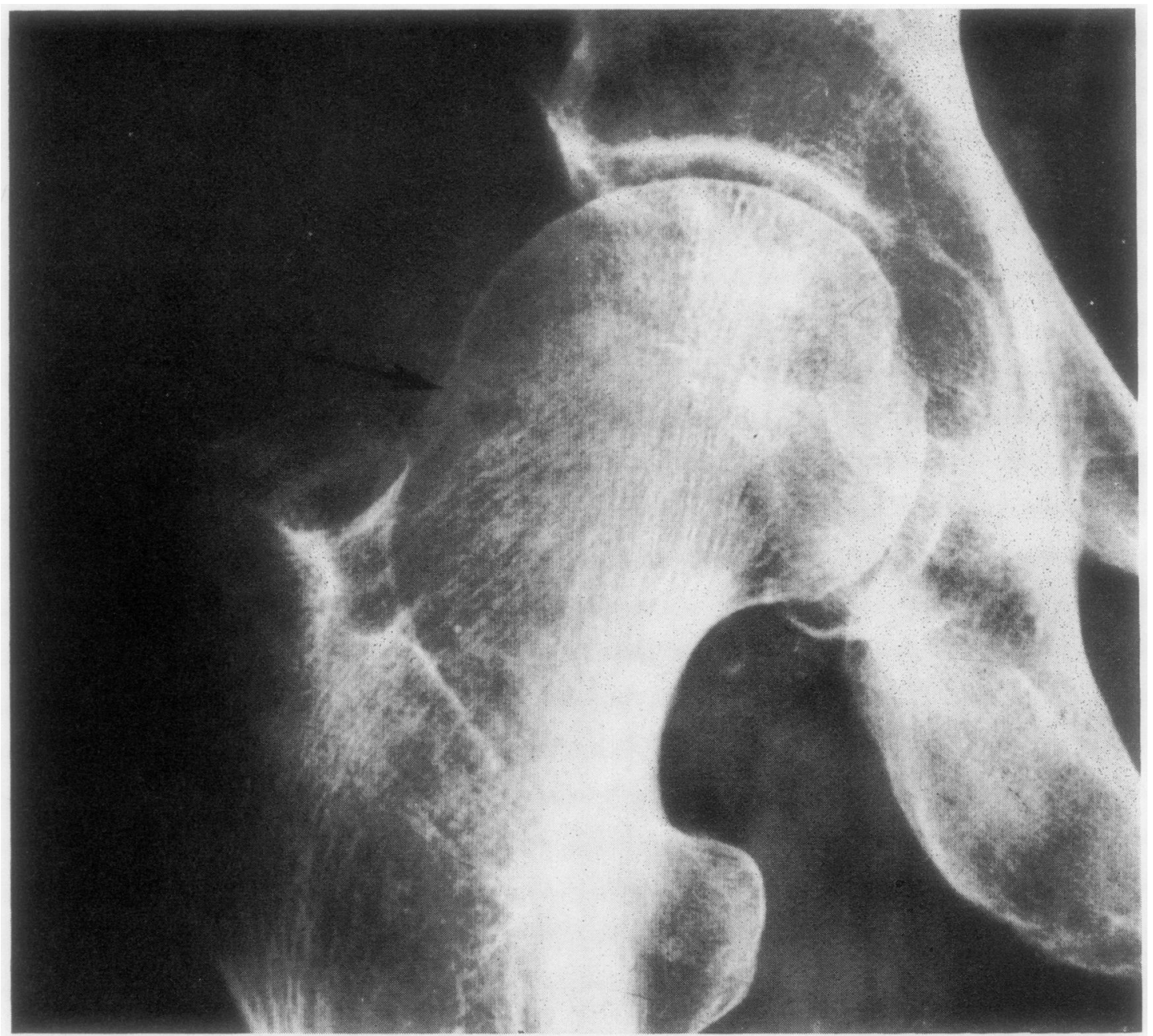

FIG. 7 Case 2. Radiograph of right hip taken 20 months previously, showing a small osteolytic lesion close to the chondro-osseous junction in the superior part of the neck.

marginal bone was absent (Fig. 9, opposite). A separate osteolytic focus, $08 \mathrm{~cm}$. diameter, was present in the subchondral region, consisting of fibrous tissue with a sparse round cell infiltrate. Fracture of the subchondral bone had occurred at this point and a communication with the joint cavity was present.

\section{Discussion}

Hunder, Ward, and Ivins (1965) reported a case of a giant rheumatoid granulomatous lesion of the right femoral neck in a woman aged 55 years who had been on steroid therapy for 11 years. This patient had not previously complained of this hip, despite a 30-year history of rheumatoid arthritis, and the femoral lesion was originally thought to be malignant. Subsequent excision and prosthetic re- placement proved the rheumatoid granulomatous nature of the lesion. This is the only previously reported case of this condition. However, a major destructive lesion of a vertebral body due to rheumatoid granulomatous erosions and subsequent pathological fracture was documented by Baggenstoss, Bickel, and Ward (1952). Vertebral involvement of this type is also well recognized in ankylosing spondylitis (Baggenstoss and others, 1952; Kanefield, Mullins, Freehafer, Furey, Horenstein, and Chamberlin, 1969; Wholey, Pugh, and Bickel, 1960). One of the cases described by Baggenstoss and others was found to have Bence-Jones proteinuria on one occasion and originally a diagnosis of myelomatosis was entertained.

The pathological findings in the two cases presented here are essentially the same. Both show re- 


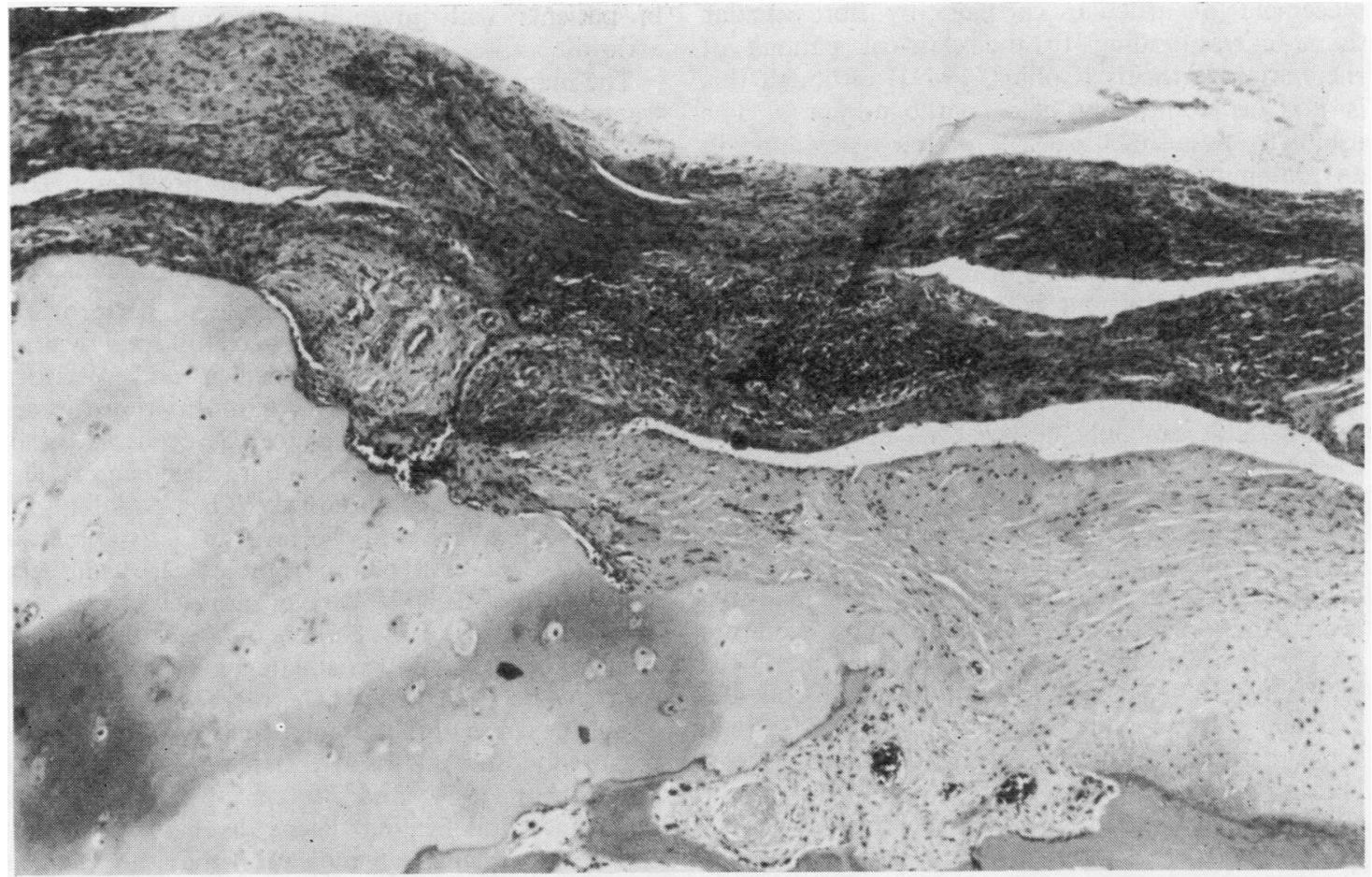

FIG. 8 Case 2. Photomicrograph of articular surface at edge of foveal region. Bone and cartilage are covered by pannus. Haematoxylin and eosin. $\times 60$.

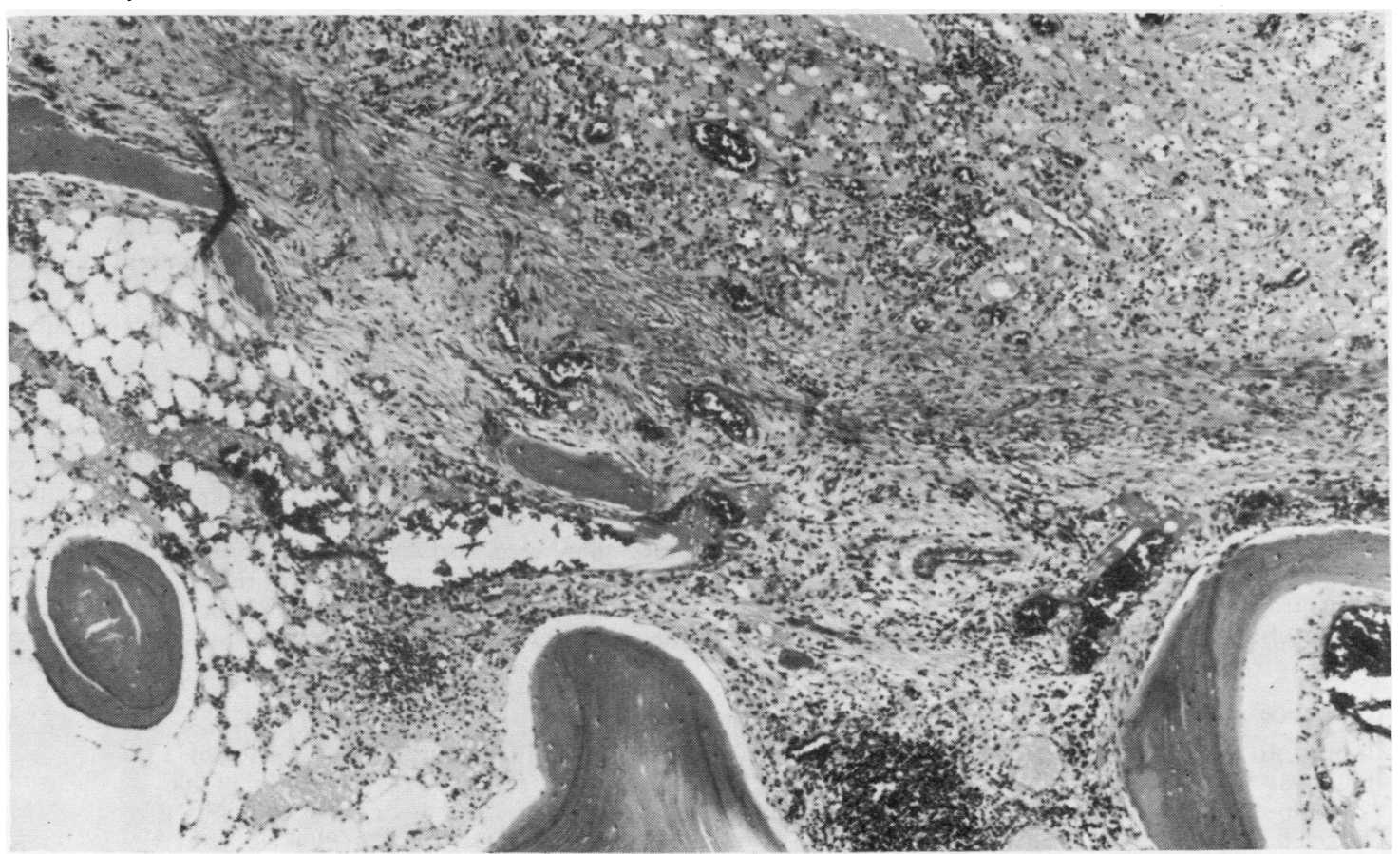

FIG. 9 Case 2. Photomicrograph of margin of osteolytic lesion. Fibrovascular tissue in upper half of field is extending directly into bone and marrow in bottom half. There is a collection of lymphocytes, adjacent to bone, at the lower edge of of the field. Haematoxylin and eosin. $\times 60$. 
placement of articular cartilage by fibrovascular tissue corresponding to the classical pannus of rheumatoid arthritis (Collins, 1949a) although this is not, as commonly held, pathognomonic. The osteolytic tissue in Case 2 is of the type found in any inflammatory process, but similar to the appearance seen frequently in the typical, small, subchondral cysts of rheumatoid arthritis (Cruickshank and others, 1954). The more fibrous, less cellular tissue of Case 1 is consistent with the findings in longstanding rheumatoid granulomata (Collins, 1937).

These findings, although non-specific in themselves, when considered with the clinical and serological data, can only be regarded as representing massive involvement of bone by rheumatoid granulation tissue.

Erosion of bone at the chondro-osseous junction is a typical early manifestation of rheumatoid arthritis (Cruickshank and others, 1954) and the lesions in these cases are presumably an exaggeration of this process. However, the large lesion of the femoral neck in Case 1 is some distance from the articular margin and may have developed from a focus of granulation tissue arising within the marrow spaces (Collins, 1949b).

Castillo, El Sallab, and Scott (1965) have suggested that there is a direct relationship between the size of rheumatoid erosions and the degree of physical activity. This, however, is not supported by the fact that Case 1 had suffered extreme lack of mobility for the previous 12 months. Neither patient received steroid therapy, which has been described as causing an acceleration of bone destruction (Murray, 1960).

In both cases reported here, giant osteolytic lesions were present with only minimal radiological evidence of hip joint arthritis and with no previous history of hip pain. It would appear that the presence and size of such erosions is not, of necessity, related to the severity or duration of the generalized rheumatoid disease. This bears out the observations of previous workers (Cruickshank and others, 1954). Pathological fractures of the femoral neck in rheumatoid arthritis have been reported (Haider and Storey, 1962; Devas, 1965), but in no case was there a pre-existing, localized, osteolytic lesion. These were thought to be stress fractures in osteoporotic bone, this view being shared by Badley and Ansell (1960) who reviewed spontaneous fractures occurring in patients with juvenile and adult rheumatoid arthritis.

The management of cases in which a pathological fracture has occurred through a giant rheumatoid granulomatous lesion of the femoral neck is excision and replacement by a femoral head prosthesis. This permits early mobilization of the patient and a rapid return to painfree hip function. Where there is severe involvement of the hip joint by rheumatoid disease, it would seem reasonable to perform excision of the femoral head and neck followed by total replacement arthroplasty (McKee and WatsonFarrar, 1966; Charnley, 1968). In those cases where no pathological fracture has occurred, as in the right hip of Case 1, the management is less clear-cut. In any such lesion there is a possibility of mechanical failure and the level of activity of the patient is obviously important in assessing the probability of fracture. Exploration, curettage, and packing with iliac bone chips is theoretically feasible. Excision biopsy and prosthetic replacement would seem to be indicated where there may be doubt about the cause of the osteolytic lesion. The presence of surrounding sclerosis is stated by Cruickshank and others (1964) and Steven (1949) to indicate quiescence and healing of the disease process and can be regarded as an indication that the lesion is unlikely to progress.

\section{Summary}

The clinical and pathological findings are presented in two cases of giant granulomatous lesions of the femoral head and neck, one bilateral and one unilateral. In each case a pathological fracture occurred and was treated by excision and prosthetic replacement of the femoral head. Neither patient had received treatment with corticosteroids.

The clinical management and histological findings are discussed.

We should like to express our thanks to Mr. J. N. Wilson and Mr. K. I. Nissen for permission to publish details of their patients, and to Dr. H. A. Sissons for his helpful criticism and assistance in the preparation of this paper. Our thanks go also to the staff of the Department of Medical Photography of the Institute of Orthopaedics (London) and to Miss M. Kimber for her painstaking secretarial assistance.

\section{References}

Badley, B. W. D., ANd Ansell, B. M. (1960) Ann. rheum. Dis., 19, 135 (Fractures in Still's disease).

Baggenstoss, A. H., Bickel, W. H., AND WARD, L. E. (1952) J. Bone Jt Surg., 34A, 601 (Rheumatoid granulomatous nodules as destructive lesions of vertebrae).

Castillo, B. A., El Sallab, R. A., AND Scotr, J. T. (1965) Ann. rheum. Dis., 24, 522 (Physical activity, cystic erosions and osteoporosis in rheumatoid arthritis).

Charnley, J. (1969) Reconstr. Surg. Traum. (Basel), 11, 9 (Total prosthetic replacement of the hip).

Collins, D. H. (1937) J. Path. Bact., 45, 97 (The subcutaneous nodule of rheumatoid arthritis). 
(1949a) 'The Pathology of Articular and Spinal Diseases', p. 183. Arnold, London.

(1949b) Idem., p. 49.

Cruickshank, B., Macleod, J. G., And Shearer W. S. (1954) J. Fac. Radiol., 5, 218 (Subarticular pseudocysts in rheumatoid arthritis).

Devas, M. B. (1965) J. Bone Jt Surg., 47B, 728 (Stress fractures of the femoral neck).

HAIDER, R., AND StOREY, G. (1962) Brit. med. J., 1, 1514 (Spontaneous fractures in rheumatoid arthritis).

Hunder, G. G., WARD, L. E., AND Ivins, J. C. (1965) Proc. Mayo Clin., 40, 766 (Rheumatoid granulomatous lesion simulating malignancy in the head and neck of the femur).

Kanefield, D. G., Mullins, B. P., Freehafer, A. A., Furey, J. G., Horenstein, S., and Chamberlin, W. B. (1969) J. Bone Jt Surg., 51A, 1369 (Destructive lesions of the spine in rheumatoid ankylosing spondylitis).

McKeE, G. K., AND Watson-FARRAR, J. (1966) Ibid., 48B, 245 (Replacement of arthritic hips by the McKee-Farrar prosthesis).

MURRAY, R. O. (1960) Brit. J. Radiol., 33, 1 (Radiological bone changes in Cushing's syndrome and steroid therapy).

Steven, G. D. (1949) Proc. roy. Soc. Med., 42, 354 (Analysis of radiographic appearances in chronic arthritis).

Wholey, M. H., Pugh, D. G., AND BiCKel, W. H. (1960) Radiology, 74, 54 (Localized destructive lesions in rheumatoid spondylitis). 